\title{
Alpha Fetoprotein Adjusted for Body Weight Measurement
}

National Cancer Institute

\section{Source}

National Cancer Institute. Alpha Fetoprotein Adjusted for Body Weight Measurement.

NCl Thesaurus. Code C147291.

The determination of the amount of alpha fetoprotein, adjusted for body weight, present in a sample. 